Orbis Tertius, vol. XXII, $n^{\circ}$ 26, e062, diciembre 2017. ISSN 1851-7811

Universidad Nacional de La Plata

Facultad de Humanidades y Ciencias de la Educación

Centro de Estudios de Teoría y Crítica Literaria

\title{
Nuevos Aires, un proyecto político cultural (1970 -1973). Entrevista a Mario Goloboff
}

\author{
María de los Ángeles Mascioto * \\ * Universidad Nacional de La Plata $\stackrel{1}{ }$, Argentina
}

La revista Nuevos Aires, dirigida por Vicente Battista, Mario Goloboff y Edgardo Trilnik, sacó once números de periodicidad trimestral entre junio de 1970 y octubre de 1973. Mediante su publicación, los directores, anteriormente colaboradores de El Escarabajo de Oro, difundieron y suscitaron discusiones político-culturales en torno a la relación entre vanguardia política y vanguardia estética en el campo nacional e internacional. El estudio de un proyecto de este tipo involucra no sólo los debates y polémicas que se promovieron en sus páginas sino también las particularidades de su materialidad (aspectos visuales, textuales, de diseño e impresión), los vínculos que estableció esta publicación periódica con una red de revistas en la que se enmarcaron su emergencia y circulación, y los modos de sociabilidad y de lectura que promovió. La charla con Mario Goloboff, uno de sus directores y reconocido especialista en literatura argentina, se centró principalmente en las decisiones tomadas en relación con todos estos aspectos.

En 2015 se digitalizó Nuevos Aires, y ahora forma parte del Archivo Histórico de Revistas Argentinas, $\underline{\text { ? }}$ donde se puede ver la colección completa con los índices de cada número. Quisiera comenzar preguntándote por sus particularidades materiales, es decir, eso que no puede verse en la digitalización, ¿cuáles son el tamaño y el formato de la revista en soporte papel?

¿Conocés Casa de las Américas? Bueno, era de ese estilo: una revista libro, inclusive la diagramación interior y los subtítulos en las páginas eran muy similares. Y así vendíamos los avisos de los primeros números de Nuevos Aires a las editoriales, como lo estoy haciendo yo en este momento: fuimos a verlo a Paco Porrúa, por ejemplo, y le dijimos "vamos a sacar una revista, que se va a llamar así, que va a tener estos artículos que estamos juntando, y va a ser más o menos de este tamaño, como Casa de las Américas, y va a estar diagramada de esa manera”. Y así vendíamos verbalmente los avisos que luego nos daban en las editoriales para financiarla. 


\section{¿Se alcanzaba a financiar con los avisos?}

Sí. Y con la venta, porque se vendía bastante bien.

\section{¿Y dónde se vendía?}

En la red de kioscos que en ese momento distribuía Pedro Sirera, que era el kiosquero del cine Lorraine. Él había distribuido antes El Escarabajo de Oro. Se vendía en los kioscos, no tanto en librerías. En algunas librerías clave la dejábamos y también se vendía en Norte, de Héctor Yánover; en Fausto.

\section{¿Te acordás cuántos ejemplares sacaban por número?}

Unos tres mil, que era una buena cantidad para la época. Y con muchos avisos publicitarios, de editoriales como Sudamericana, Losada, Ediciones de la Flor, Galerna, Siglo XXI, Nova, Proyección, Fabril.

\section{¿Cuáles fueron los orígenes de la revista?}

Nosotros nos fuimos de El Escarabajo de Oro porque nos dijimos y le dijimos a la gente que se quedó, que no nos bastaba con estar en una revista literaria para los movimientos político-culturales que había en la época, y que queríamos sacar una revista más de política cultural que exclusivamente literaria, y fue lo que hicimos. Nos juntamos con gente que estaba en El Escarabajo..., fundamentalmente Vicente Battista, Edgardo Trilnik y yo, y nos acompañaron algunos otros amigos.

Y además era una alianza cultural-política porque Trilnik acababa de egresar de Filosofía y Letras y se decía peronista de la nueva época, así que en el campo cultural nos juntamos_gente de izquierda que no había estado en el peronismo, y gente que en ese momento se incorporaba al nuevo peronismo. Yo venía del marxismo, también Battista, no Edgardo Trilnik, pero conocía bastante de política y de marxismo, era más jovencito. Y queríamos darle una dimensión política a la revista. Tuvimos la desgracia de que a los pocos meses de haberla fundado Edgardo tuvo un accidente y falleció... seguimos sacándola Vicente y yo.

\section{¿Los tres se conocieron en El Escarabajo de Oro?}

Sí, yo estuve en el consejo de redacción, inclusive, uno o dos años.

\section{¿De qué manera emerge la revista en el campo de publicaciones de la época?}

Queríamos ocupar una franja que estaba desocupada, porque había una revista literaria como El Escarabajo...; una revista de ciencia literaria, que era Los Libros, en la que había gente más o menos coincidente con nosotros en lo que concernía a las ideas políticas, pero que veían la cultura y la literatura desde otro ángulo; y había otra revista como Crisis, aunque fue un poco posterior, del ’73, con una orientación más peronista.

En el primer número aparece mucho la relación entre vanguardia política y vanguardia artística; la revista pareciera mostrar un interés mayor en la cuestión política que en la literaria ¿Hay en estas elecciones una respuesta a la postura de El Escarabajo de Oro?

No hubo disidencia política con Abelardo Castillo en ese momento. En realidad, la génesis de Nuevos Aires es más profunda. Nosotros le decimos a Abelardo: "Mirá, hay que transformar El Escarabajo... en otra cosa, los tiempos que corren son para una revista de política cultural”. Acababa de suicidarse José María Arguedas en Perú, se decía que ante el fracaso de la revolución peruana; crecía y resistía la revolución cubana; se expandían por América Latina nuevas formas de resistencia a las políticas imperiales y a las oligarquías nativas; y todo ello iba de la mano 
con un nuevo arte latinoamericano y una nueva literatura (o así los veíamos...). Es decir, le planteamos cómo veíamos la situación. Y le propusimos armar una revista juntos (no dirigida por él, claro). Abelardo nos dijo que lo iba a pensar y en unos días nos dijo que la hiciéramos por nuestra cuenta, que él se quedaba con El Escarabajo...

El Escarabajo... dejó de salir en octubre del '69 y después volvió en noviembre del '70; ¿esa interrupción jugó algún rol en la salida de Nuevos Aires?

No. Sé que se fue mucha gente de El Escarabajo... por cuestiones políticas o personales. Yo supongo que habrá cerrado en ese momento por dificultades económicas, porque no tenía muchos avisos, la revista vivía de la venta. Nosotros, en cambio, cuando sacamos Nuevos Aires, lo primero que hicimos fue hacer una cadena de avisos y publicidad, como hacen hoy todos los medios. Desde el primer número salimos con muchos avisos, la revista nunca nos dio pérdidas, nunca tuvimos que poner plata arriba, cosa que en cambio la gente de El Escarabajo... sí hacía.

A veces el primer número de una revista se piensa de manera programática, ¿ustedes cómo planearon el armado del número 1 de Nuevos Aires? ¿Lo pensaron en relación con lo que se publicaba en El Escarabajo de Oro, emergió en polémica con esta u otras publicaciones...?

Yo no sé si se puede caracterizar una revista por lo que va a sacar en ese primer número. Recuerdo que en ese momento, una vez que salió, nosotros consultamos a alguna gente qué les parecía y Ricardo Piglia nos dijo: “una revista es una colección”. Un gran acierto de Ricardo: hay que ver varios números para ver qué es; se va haciendo, además. Él había sacado ya una revista y estaba vinculado también a Los Libros.

Pero no hubo una competencia o polémica entre Nuevos Aires y El Escarabajo... Cuando salió nuestra revista nosotros dejamos de pensar en la de Abelardo, pensábamos en otras cosas, en todo lo que estaba pasando en América Latina en los tempranos '70, y en lo que estaba pasando en el mundo y Argentina, en el mundo cultural y político. Nuestro referente no fue nunca El Escarabajo..., al contrario, quisimos hacer una cosa diferente.

En cuanto al propósito de política cultural de Nuevos Aires, algo que aparece en los dos primeros números es la polémica entre Cortázar y Collazos.

Sí, yo no te diría que la nota de Cortázar fue para nosotros central en ese aspecto. En la presentación de esa nota yo digo que Collazos "le ponía a Cortázar los más serios escollos", cosa que hoy no pienso para nada; creo que Cortázar salió muy airoso de esa polémica. Sí aportó a los vínculos entre vanguardia artística y política porque ahí se discutió mucho sobre líneas estéticas, y publicarla en Argentina fue también un hecho político, porque apareció por primera vez en Marcha, que estaba censurada acá y entraba clandestinamente.

¿La publicación de esa polémica tuvo repercusiones en el campo intelectual local? Lo pienso también en relación con el debate sobre intelectuales y revolución que sale en el número 6.

Sí, por supuesto que tuvo repercusiones. Pero había otras notas más atrevidas desde el punto de vista político. Publicamos un artículo de Guillermo Arce Martínez, un cura cubano, sobre el papel de la iglesia en una sociedad socialista, que despertó mucho interés; y también trabajos de Adolfo Sánchez Vázquez, un filósofo marxista español exiliado en México, donde dio clases y publicó muchísimas cosas. Una de las notas de Sánchez Vázquez la tomamos de Casa de las Américas, otra nos la mandó después de que nosotros le enviáramos a él el primer número. 


\section{¿Hay un hilo conductor de todos los artículos políticos?}

Sí, me parece que se ve un hilo conductor que es o sería el de un pensamiento que queríamos progresista, de izquierda y algo original para ese momento tan especial que fue el comienzo de los setenta.

\section{¿Cómo fue la circulación de Nuevos Aires en el exterior?}

Salía mucho, la mandábamos a muchos lugares. Abrimos una casilla en el Correo Central y desde ahí la difundimos bastante, la enviamos a toda Latinoamérica, España, Francia, Rumania, Italia.

\section{¿Cuál es el origen del nombre?}

Nosotros frecuentábamos mucho a Leopoldo Marechal, nos habíamos hecho muy amigos de él. Un día fue a verlo Edgardo Trilnik, a comentarle que estábamos sacando una nueva revista y que queríamos ponerle como nombre Adán Buenosayres en honor a él, y Leopoldo le dijo que no, que no lo hiciéramos. Fue un gesto más bien de modestia de su parte, porque nadie es dueño de los títulos. No obstante nos dio una nota especial para la revista, que apareció en el primer número y que se tituló "El poeta depuesto" (hace poco publiqué un artículo contando esta historia). $\underline{3}$ Entonces cambiamos el título por Nuevos Aires, que nos pareció interesante como renovación de los aires político-culturales.

\section{Someramente, ¿cómo es la historia de tu militancia política?}

Yo estuve en la Fede [Federación Juvenil Comunista] desde muy jovencito. En ese momento era un marxista crítico, crítico del Partido Comunista que había traído el marxismo a América Latina, crítico de las posturas estéticas de la izquierda internacional, de las líneas de política cultural y de las líneas estéticas, del realismo socialista. Cuando sacamos la revista, yo era un francotirador independiente, no estaba en ninguna organización política. Sí estaba en una cooperativa editorial que se llamaba "Hoy en la cultura” y pensando en sacar revistas como la mía, pero ya había salido de la universidad, hacía poco. Leía en la época literatura de la izquierda clásica y de la izquierda renovadora, revistas como la Monthly Review, Les Temps Modernes, Il Manifesto. Buscaba mucho, por fuera de Argentina, ver qué decían los italianos de esto, qué decían los alemanes, los franceses, cierto pensamiento español; ésa era la red que un poco en abstracto yo me armaba.

\section{¿Y cuál era la orientación política de Nuevos Aires?}

La orientación de la revista era de una izquierda amplia, no muy ligada a los intereses y deseos de la URSS, más bien un poco pro-China, en esa división que se dio en los sesenta y setenta en el mundo socialista. Era también crítica del realismo socialista, del dogmatismo cultural: más bien se vinculaba ideológicamente a las izquierdas latinoamericanas independientes, pro-cubanas, pero también críticas. Recogíamos materiales del pensamiento de una izquierda crítica de diversos lugares.

En ese momento, en el movimiento político comunista internacional había muchas internas, estaba la disidencia china, los soviéticos y algunos países del bloque que estaban por fuera: Yugoslavia, notoriamente, pero también Rumania, Polonia.

\section{Hay una polémica ahí, la del caso Padilla.}

Sí, nosotros proponemos una discusión que no fue bien vista por los cubanos, sobre todo porque abrimos todos los ángulos de la polémica. El affaire Padilla se inició por un artículo que publicó la revista Verde Olivo, que era del ejército cubano, donde se preguntaban cómo le habían dado un premio a ese poeta "antirrevolucionario". 
Imaginate la lectura que podía hacer sobre un libro de poemas una revista de ese estilo.

\section{¿Y cómo se llevó a cabo ese debate en torno al caso Padilla que luego se transcribió en Nuevos Aires?}

Lo hicimos en la casa de Vicente Battista, fue una reunión en la que participaron León Rozitchner; que asumió una actitud muy pro-cubana; Marcos Kaplan, profesor adjunto de Silvio Frondizi en la cátedra de Derecho Político de La Plata (que discutió mucho con Ricardo Piglia); Oscar Landi, Juan Carlos Portantiero; Noé Jitrik; José Vazeilles; Mauricio Meinares, que era un nombre falso, un seudónimo de un amigo que militaba en el Partido Comunista Revolucionario. Pusimos un grabador y luego desgrabamos todo. Algunos de ellos participaron mediante un texto porque no pudieron estar ese día, les pedimos una nota hablando del tema.

\section{Participó un joven Ricardo Piglia, muy discutidor. 4}

Sí, discutió mucho con Kaplan. Ricardo decía en ese momento que hacían muy bien los cubanos, que había que mandar a los intelectuales a la zafra.

\section{¿Por qué ese conjunto de gente, cómo surgió la selección de los participantes del debate?}

Pensamos en un conjunto de gente que se ubicaba en una izquierda crítica, que no era dogmática ni del partido comunista a la vieja usanza ni trotskista de vieja data.

\section{¿Qué conclusiones sacaron ustedes, los directores, de ese encuentro?}

Que fue muy rico, muy interesante, queda como testimonio de una época. Intervino la gente más interesante que circulaba en el campo intelectual argentino en ese momento: Landi, Portantiero, Piglia, Jitrik. Nadie asumió posiciones muy estudiadas, estábamos en un laboratorio.

\section{¿Padilla dónde publicaba por ese entonces?}

Hasta ese momento trabajaba en el periódico Revolución y había acompañado a la revolución desde joven. Es cierto que su libro Fuera de juego tenía poemas críticos de algunas cuestiones y medidas o políticas de la revolución cubana.

\section{El editorial del número 5 que escriben ustedes tiene un título bastante fuerte: “Cuba ¿̇revolución en la cultura?”}

Sí, no les gustó nada a los cubanos. No aceptaban críticas, así fueran de amigos. Sartre había sacado un libro sobre la revolución cubana, Huracán sobre el azúcar, saludando la revolución y era un cubanista eminente, también Passolini y Vargas Llosa y toda la gente que andaba por Europa. Sin embargo, cuando reaccionan por el caso Padilla, Fidel Castro los ataca fuerte.

\section{¿Cómo funcionaban las redes intelectuales en esa época, el intercambio y envío de revistas a otros países?}

Acá recibíamos muchas revistas, de Rumania recibíamos una que se llamaba Secolul 20, también de Francia recibíamos Tel Quel. Con los franceses teníamos mucho intercambio porque yo estaba conectado con muchos intelectuales independientes de Francia, entre ellos Albert Memmi, uno de los grandes teóricos del fanonismo. Y a toda esa gente la conocía por varias vías, esto que vos decías: la red intelectual. Acá llegaba un periódico, que hizo época en toda América Latina, que fue Marcha, que era una guía para el pensamiento de izquierda 
latinoamericano. Este periódico, uruguayo, publica el manifiesto del Che Guevara sobre el hombre nuevo, y mucho material de esa línea.

Con Marcha establecimos un contacto inmediato en Uruguay, porque aquí no llegaba la revista, el gobierno de Onganía había prohibido la entrada. Y como no circulaba acá, republicamos la polémica entre Cortázar y Collazos que publicaron ellos originariamente.

\section{¿Cómo eran esos circuitos de intercambio con otras publicaciones?}

Nosotros republicamos muchas cosas. En una época salía la Monthly Review, una revista de las izquierdas norteamericanas que fue muy famosa durante muchos años. Robábamos algunos artículos a este tipo de revistas, pero era un robo político, para que entraran en el país. Casa de las Américas acá no llegaba, tampoco la podían mandar por correo, circulaba de manera muy clandestina.

Es decir que la revista era un lugar para hacer circular materiales que no estaban acá, ¿y también había materiales que se pedían?

Sí. Albert Memmi me ha mandado artículos, un teórico fanonista muy inteligente, judío. Había también gente de España como Fernando Quiñones, Rafael Guillén, Félix Grande que nos mandaban textos para publicar. Cubanos como Fernández Retamar. Adolfo Sánchez Vázquez también nos envió un artículo. De aquí, Horacio Salas, Hugo Acevedo, León Pomer y tantos otros nos enviaban notas para la revista.

\section{¿Y cómo establecieron el vínculo con los colaboradores extranjeros?}

A Fernández Retamar lo había conocido a través de su poesía, nos conocíamos también por carta, porque él nos mandaba, cuando podía, Casa de las América. Teníamos una relación personal, más bien poética.

Aparecen también muchos poetas chilenos, sobre todo en el número 3.

Bueno, a los poetas chilenos los conocí en Chile. Yo fui invitado a un congreso literario en la Universidad de Valparaíso en el '70 y ahí nos conocimos con varios de ellos. Teníamos contactos culturales y políticos, como con otros colaboradores de la revista.

\section{¿Esa selección de poemas chilenos del número 3 la hicieron ustedes, los directores?}

Sí, la hicimos nosotros. Fue un número dedicado a Chile; el editorial lo escribí también yo. Probablemente Julio Huasi nos haya pasado algo. Grandes poetas todos: hicimos una apuesta fuerte con Pablo de Rokha como la contracara de Pablo Neruda, también están Gonzalo Rojas, Enrique Lihn, Fernando Alegría, muy buenos poetas.

Neruda aparece hacia el final del editorial que mencionás. Un editorial muy cauteloso sobre la asunción de Salvador Allende, bastante premonitorio y al mismo tiempo reflexivo sobre los modos de intervención de los intelectuales en los acontecimientos políticos. ¿Cómo lo ves hoy?

Sí, ese fue un editorial muy trabajado, y donde advertimos bastante. Decimos: cuidado, no terminemos como terminó ${ }^{5}$.

¿Después de ese número siguieron pensando, discutiendo sobre el proceso chileno en la revista?

Sí, y a medida que avanzaron los acontecimientos, cada vez más en la línea preventiva y “anti-ilusiones”. 


\section{¿Qué leías en ese momento?}

Pavese, Borges, Conti. Lo único que yo escribí en Nuevos Aires, que salió como anticipo en La Opinión, fue un artículo sobre Haroldo Conti. Los diarios publicaban en ese entonces anticipos de lo que salía en las revistas.

\section{Y las tapas de la revista ¿quién las hacía?}

Nosotros. Tomábamos dibujos, fotos, recortábamos y armábamos la tapa nosotros mismos, no teníamos diseñador. Vicente Battista se daba mucha maña, él iba a la imprenta, armaba la tapa.

\section{Es muy lindo el isotopo de Nuevos Aires.}

Sí, es un viejo grabado que encontramos en un libro, o en un diccionario, y que lo ampliamos, y pensamos que podía ser una buena tapa para el primer número. Luego se transformó en el logo de la revista.

\section{¿Qué otras revistas circulaban en la época en Argentina?}

Las del mercado, de amplia circulación: Panorama, Primera Plana, Confirmado, Análisis, Redacción, revistas que sacaban las grandes editoriales. Paco Urondo, por ejemplo, le hizo un reportaje a Cortázar para la revista Panorama en diciembre del '70, cuando volvió de Santiago de Chile porque había ido a la asunción de Allende. $\underline{6}$

Como revistas de grupo, para la época circulaba El Escarabajo de Oro, tal vez El Barrilete, ${ }^{\underline{7}}$ que salía en Avellaneda; Pasado y Presente, que ya no salía $\underline{\underline{B}}$ pero algunos colaboradores eran muy cercanos a Nuevos Aires; La Rosa Blindada, que apareció un poco antes.

\section{¿A Julio Cortázar ya lo conocías en ese entonces?}

No, yo no tenía contacto con Cortázar, nunca siquiera lo había visto. Sí él tenía contacto con la gente de El Escarabajo... Me fui haciendo más cortazariano después, casi te diría con la biografía, $\underline{9}$ cuando empecé a trabajarlo más.

Justamente, ahora que mencionás las revistas de amplia circulación, en el número 1 de Nuevos Aires se publica un artículo de Horacio Salas $\underline{10}$ donde se cuestiona, en cierto modo, la irrupción de semanarios y la presencia en ellos de escritores provenientes de las revistas literarias. Los semanarios se habrían adueñado de las columnas de revistas de información general, dice Salas, estructurando un nuevo tipo de crítica que trataba de desentrañar la visión del autor latinoamericano, ¿coincidís en eso?

No de una manera tan estructurada, pero eso es lo que pasó. Llegaron las revistas de actualidad -Primera Plana, Confirmado- y ahí irrumpieron escritores, críticos, gente que venía de la Facultad. Yo conocí personalmente a Juan Gelman en Confirmado, y en Primera Plana trabajó Tomás Eloy Martínez. Hacían una crítica comentada, del gusto, que en los setenta yo habría llamado "crítica poco científica”.

\section{Salas dice que en ese momento surge el escritor crítico.}

Yo creo que sí, que ese es el momento en el que se produce ese tipo de crítica. Él está dando cuenta de este fenómeno y está hablando también de él. 
Me llamó la atención que ustedes, los directores, no publicaron artículos en Nuevos Aires. Vos publicás sólo uno y Battista ninguno ¿A qué se debe esa decisión?

Esa fue una de las primeras decisiones que tomamos. No queríamos que fuera una revista para publicar nosotros dos, o nosotros tres; en uno de los últimos números escribí una nota porque alguien me dijo que tampoco era necesario llevar esa idea a un extremo. Entonces decidí publicar el artículo sobre Haroldo Conti.

Nuevos Aires se publicaba cada tres meses, imagino que eso les permitía disponer de tiempo para conseguir los artículos, traducir, etc.

Claro, la revista tenía que tener cierta periodicidad, pero no disponíamos de tiempo ni de dinero como para sacar un ejemplar por mes. Había que conseguir los artículos -no pagos, porque eran colaboraciones políticas, ideológicas. En la actualidad sería imposible sacar una revista de este tipo. Intelectuales de mucho prestigio nos daban sus artículos gratuitamente. Hoy, gente como Albert Memmi cobraría bastante por mandar una nota de diez páginas.

Al final de cada número aparece un adelanto de lo que se iba a publicar. Pensaba en los tiempos de preparación de una revista trimestral, en la búsqueda de notas que debería ser previa a ese anuncio, ¿cómo se planeaba lo que iba a aparecer en el número siguiente?

No teníamos el número armado sino pensado, propuesto. En algunos casos anunciamos cosas que luego no aparecían. Una revista también es un armado: nosotros pedíamos colaboraciones, a veces nos la daban, a veces no. Cuando nos la daban, nos mandaban notas de distinta extensión: uno mandaba una nota de doce páginas, otro una de veinte, otro de cuatro, y nosotros la íbamos armando como podíamos, porque teníamos un límite de páginas para publicar.

Es una de las particularidades de la prensa: la limitación del espacio para escribir.

Claro, cuando a uno le piden una nota ya sabe con cuántos caracteres con espacio dispone, eso es fantástico porque uno aprende mucho a escribir, aprende de la economía del espacio. Te das cuenta que podés decir en cuatro mil caracteres con espacio lo mismo, o mejor, que lo que decías en doce mil. Y si el texto va acompañado por ilustraciones son menos caracteres aún.

¿En alguna ocasión tuvieron que recortar alguna nota para que alcanzara justamente la cantidad de caracteres por página, o la cantidad de páginas?

No, y tampoco pedíamos a los autores que nos mandaran notas de un determinado número de páginas, el armado de la revista lo hacíamos nosotros.

Mencionaste la cuestión de las ilustraciones y recordé que algunos números de Nuevos Aires tienen imágenes en el interior, otros no, ¿cómo se decidía en qué números y qué imágenes se incluían?

Las imágenes nos encarecían mucho la producción, sobre todo el color. Otro trabajo, además, era buscarlas, tenerlas. Algunas las hemos sacado de publicaciones europeas, pero no era sencillo incluir ilustraciones.

Los textos que publicaron de Carpani y Sánchez Vázquez, entre otros, reflexionaban sobre el arte revolucionario. En un caso se hace referencia a las ideas de Lenin sobre el arte, en otro sobre Fidel Castro. ¿Qué pensaban ustedes sobre la intromisión de los líderes políticos en los debates sobre una estética revolucionaria? 
Pensábamos críticamente, no coincidíamos en este aspecto con el papel que le asignaban al arte y a la literatura, la función que ellos decían debían cumplir en la sociedad, porque ellos creían que el arte era también un medio de comunicación para las masas que podía servir, entonces, para transmitir determinados contenidos. Y por eso generalmente eran partidarios de un arte contenidista, realista. No veían otras funciones sociales que cumplen el arte y la literatura sin proponérselo, por lo que son, y que pueden llegar a ser más importantes que las que los líderes políticos creen que pueden cumplir. Esta ha sido la polémica en el campo del marxismo desde los tiempos más remotos hasta hoy.

\section{Cuba, sobre todo por ese entonces, era un lugar de expansión de las actividades artísticas y literarias.}

Sí, un lugar de expansión que no había tenido nunca ningún país latinoamericano, y además las cosas que ellos hacían en la práctica: la campaña de alfabetización masiva, en la que iban voluntarios a recorrer la isla; la creación de una editorial nacional, del Estado, al frente de la cual estaba Alejo Carpentier. Empezaron a publicar de todo, autores norteamericanos, rusos, franceses, lo que fuera, y editaban libros en cantidades astronómicas para lo que era el país.

\section{¿Las traducciones las hicieron ustedes?, ¿se traducía el artículo completo o se quitaban cosas por cuestiones de censura o de espacio?}

Traducíamos nosotros, sí. No, no hubo censura. Pensá que nosotros publicábamos tapas muy fuertes y no ha pasado nada. También hay que decir que la revista cerró en un momento oportuno.

\section{¿Cuál fue el motivo del cierre?}

El último número lo sacaron cuando nosotros ya no estábamos aquí, porque, por esas redes políticas y culturales de las que venimos hablando, le llegó un ejemplar de Nuevos Aires a gente de Francia y Jean Andreu me escribe a finales del '72, diciéndome que se iba a ir su lector argentino a Estados Unidos y si yo estaría dispuesto a hacerme cargo del lectorado; y yo le digo que sí. Los últimos días de diciembre pasé por el Correo Central a recoger la correspondencia de la revista y me encuentro con una carta de él diciéndome que inesperadamente Walter Mignolo, que era el lector que se iba a ir a mediados de año, se iba en ese momento dejando el lectorado vacío. Me voy entonces el 15 de enero del ’73 a Francia para cubrir ese puesto.

Vicente Battista se va a Italia al festival de Locarno, a presentar una película de corte político-fantástico, Esperando el regreso de Holloway, y se queda en España. Amigos que habían estado en la revista con nosotros siguieron sacándola hasta el último número en el que publicaron un editorial sobre los fusilamientos de Trelew.

\section{¿Ustedes supervisaban esas notas de los últimos números?}

No supervisábamos, pero observábamos. Después dejó de salir porque ya no podía salir más.

\section{NOTAS}

1 Esta entrevista fue realizada en el marco de los proyectos de investigación "Literatura argentina del siglo XX y publicaciones periódicas: emergencias e interacciones formativas” (UNLP) y "Las publicaciones periódicas como contextos formativos de la literatura argentina (siglo XX)” (Agencia - PICT), dirigidos por Geraldine Rogers, quien estuvo presente en uno de los encuentros. 
$\underline{2}$ La colección completa se encuentra digitalizada en el repositorio digital del Archivo Histórico de Revistas Argentinas, puede consultarse en: http://www.ahira.com.ar/nuevosaires.php

$\underline{3}$ El artículo, titulado "El poeta depuesto", puede consultarse en https://www.pagina12.com.ar/diario/contratapa/13-274698-2015-06-12.html

4 Piglia expone su perspectiva sobre este debate en sus diarios, cfr. Los diarios de Emilio Renzi. Los años felices. Buenos Aires, Anagrama, 2016, p. 273 y ss.

$\underline{5}$ El editorial "Las otras caras de la moneda", sobre el triunfo de la Unidad Popular, se publicó en el número correspondiente a diciembre de 1970, enero y febrero de 1971. En él, Goloboff advierte: "Efectivamente: se ha llegado, se ha obtenido el Gobierno ¿También el Poder? ¿Quién 'mandará parar' cuando ante las reformas, las nacionalizaciones y las expropiaciones de sectores afectados se opongan por la fuerza a perder sus bienes y privilegios; cuando las agencias noticiosas empiecen a hablar de dictadura y caos económico; cuando gobiernos vecinos o lejanos se movilicen para cerrar la herida; cuando los Carabineros se resistan; cuando las Fuerzas Armadas formulen planteos, exijan rectificaciones, cambios. ¿Quién? ¿Qué Poder?” (Nuevos Aires, n 3, Año 2, p.4).

6 Francisco Paco Urondo (1970) “Julio Cortázar: el escritor y sus armas”, Panorama n 187, noviembre de 1970.

Z El Barrilete se publicó entre 1963 y 1974, bajo la dirección de Roberto Santoro.

8 Pasado y Presente (primera época) salió en Córdoba entre 1963 y 1964, en su primer año dirigida por Oscar del Barco y Aníbal Arcondo, y desde el segundo año también por José Aricó, Samuel Kierczovsky, Juan Carlos Torre, Héctor Schmucler, César Guiñazú, Carlos Assandourian, Francisco Delich, Luis J. Prieto y Carlos Giordano.

9 Mario Goloboff. Julio Cortázar, la biografía. Buenos Aires, Seix Barral, 1998.

10 Horacio Salas. “En defensa de la crítica”, Nuevos Aires, n 1, Año 1, p. 47. 